\title{
A Resource Based View Of Quality: Managers' Role In Developing Quality As A Weapon Of Competitive Advantage
}

Deepak Kumar Subedi, (Email: subedi@marshall.edu), Marshall University

\begin{abstract}
Managers with requisite knowledge and skills can play crucial role in developing quality as resource for competitive advantage. Their skills, experience, and knowledge determine how quality is conceptualized. And once conceptualization is complete, their skills also determine how quality targets are achieved. Again at any point in time the level of excellence in products and processes can only be built upon what has already been achieved. This article ties together these important issues to develop a conceptual model using theories on quality, knowledge and learning.
\end{abstract}

\section{INTRODUCTION}

$\mathrm{n}$ spite of established reputation and technical supremacy, American companies have lost their market
share to foreign (especially Japanese) competition since 1980's. Japanese companies got the inroad
because of the higher quality of their products (Grant, 1991; Womack et al., 1990; Economist, 2005). Higher quality leads to the increased market share and also higher profit margin (Hendricks and Singhal, 1997). Toyota is the burning example of the success with the high quality products. American customers rate Toyota cars to be of the highest quality. Toyota's profit margin is higher than that of any of their competitors. And, their market share is increasing. Recently they even beat Ford to become the number two car producer in the world (Power Report, 2003; Economist, 2005).

These successes of Japanese companies have encouraged American managers to emulate Japanese quality level. As a result, quality of American products (including motor vehicles) has improved enormously. But, Japanese have moved further ahead, and American companies are still trying to catch up (Power Report, 2003; Economist, 2005). Thus, in spite of the improvements, competitive position of American companies vis-à-vis their Japanese counterparts have not improved.

At the fundamental level Japanese companies' advantage lie not just in the quality of their products, but in their ability to continuously learn and improve upon what have already been achieved (Senge, 1992; Economist, 2005). Managers in their organizations have provided leaderships in developing frameworks to understand quality and needs for improvements. Their leaderships are also apparent in the implementations of those concepts (Womack et al., 1990; Economist, 2005).

This article looks at the previous works in the areas of knowledge and quality (Kim, 1993; Mukherjee et al., 1990) and, learning and quality (Fine, 1986; Li and Rajagopalan, 1998, 1997) to explain the relationship between the managers' level of conceptual and operational skills and the quality of the product or service of the organization. Since they are path dependent and not easy to replicate, skills, knowledge, and quality are unique to each organization. Such unique resource can bestow advantage to a particular organization over its competitors. This article ties the works in the areas of skills, learning and quality with the resource based view of firms (Diericks and Cool, 1989) to show that quality is a source of competitive advantage in the market place. 


\section{LITERATURE REVIEW}

One way or the other every organization must learn in order to survive and grow. The American car industry went through a steep learning curve after the introduction of the mass production earlier this century (Fine and Raff, 2001; Ghemawat, 1985). Learning in this context can be taken as the organization's ability to produce the same product with consistent quality and less cost.

Such learning gets embedded in the company's routine, and makes into common organizational memory. The institutionalization of learning takes place because of the routine. But in the long run when challenged by the foreign competitors, the very routine or habit thus acquired also became a hindrance limiting their ability to learn to adapt to the new environment (Helper et al., 2000).

In the face of intensifying challenge, organizations have to institutionalize a continuous improvement process. For successfully carrying continuous improvement firms need to break the established routine with intentional rounds of evaluations and improvements (Davenport and Short, 1990). Japanese managers make conscious efforts to take their firms through the process of breaking the established routine. This continuous endeavor in learning and improving is identified as one big reason that took Japanese firms ahead of their American counterparts within a short period of time (Tyre and Orlikwski, 1993; Senge, 1992).

Any student of management can easily identify the learning curve. The steepness of its slope represents how quickly and effectively organizational learning take place. But it is shown that it varies from one industry to another. It can also be different from one firm to another within the same industry, and even among different projects within the same firm (Dutton and Thomas, 1984). Managers' challenge is to understand the reasons behind these learning and see how they can influence their courses (and hence the slope of the curves) for the benefit of their organization.

Learning does not always need concerted effort. For example, American car industry at the turn of last century went through a steep learning curve. But the learning came mostly as a byproduct of massive scale of production. On the other hand, the current Japanese practice of learning is learning by planning. Only planned learning can be effective in improving quality of complex products with complicated processes, such as cars or integrated circuits. Only this learning helps to develop quality as a source of competitive advantage (Hatch and Mowery; 1998; Li and Rajagopalan, 1998; Dutton and Thomas, 1984).

Higher-level quality as a target can be used to start (or sustain) learning process. Such quality target sets the pace of learning. If skillfully managed, higher level of quality target moves organization through a steeper learning curve. The next level of quality in turn depends on the level of excellence already achieved. Thus managers' skill in setting quality target and achieving it lead organizations to a virtuous circle of higher quality and cumulative learning (Fine, 1986; Li and Rajagopalan, 1997, 1998; Senge, 1990). Japanese car industry set a very high standard of quality, and went through a very steep learning curve. Thus they could achieve higher quality with lower cost compared to their competitors (Fine, 1986).

For quality management, first step is to conceptualize what quality is. It is like finding the right target pertaining to quality. Once conceptualized, it has to be operationalized. Operationalization means defining steps for achieving the target set in the first step. Both steps require knowledge on conceptual and operational aspects of quality on the part of managers (Mukherjee et al., 1990). The improvement in quality is the outcome of this process of conceptualization and operationalization. The improvement in quality in turn contributes to the process of conceptualization and operationalization (Kim, 1993). This overall conceptual scheme is shown in figure 1.

At any point of time the current level of quality depends upon previous level of quality and the rate of improvement upon it. This makes quality one of the resources that is "non-tradable", "path dependent" and "not easy to duplicate." Besides, it also suffers from the "diseconomy of time compression." (Diericks and Cool, 1989) Organizations that lag behind in quality play the catching up for a long time. For this reason quality is a source of competitive advantage (Wernerfelt, 1984; Barney, 1991). 


\section{THE MODEL}

Based on the framework of conceptual scheme presented above, the operational model is developed. Since only the learning by planning can be the source of competitive advantage, this model considers only the effect of learning by planning on quality. Secondly, the model looks only at the process quality. Process quality is the outcome of excellence achieved in manufacturing process. Besides process quality inspection and rework can also improve quality of the final products, but such improvements cannot be the source of the competitive advantage (Li and Rajagopalan, 1998).

In the model, the problem definition and setting of the quality target determine improvements required. These three constructs together form the definition of quality. The improvements required and the supervisors' capability directly affects the rate of improvement in process quality that in turn affects the competitive advantage. Supervisors' capability and rate of improvement in process quality are parts of implementation of quality process as defined above. The details of each of the constructs are discussed in the paragraphs below.

\section{Problem Definition}

Problem definition is the first step in for any disciplined problem solving effort, but to rightly define a problem is not simple. A strong conceptual knowledge is required in order to be able to define problem and forecast its consequences on one's organization (Mukherjee et al., 1998). For example, in Toyota Production System inventory, rework and even quality inspection are identified as waste (Womack et al., 1990, pages 53 and 62). Before this, neither the waste nor huge cost of such waste was obvious to any other manufacturers.

Learning curve literature stresses a need to understand the underlying causes behind the stiffness of its slope. Generally learning curves are drawn with the aggregate data pertaining to the whole company. Such data are too noisy to have any meaningful interpretation (Zangwill and Kantor, 1998). The inability of managers to disaggregate the data, and attribute cost to the relevant processes is one of the reasons why they fail to exploit learning curves to the benefit of their companies (Ghemawat, 1985).

At the most disaggregated and fundamental level, the learning curve is a straight line with a finite ending. If the cause effect is truly understood and learning curve is correctly disaggregated, particular problem can be completely solved. Toyota management's success in achieving zero defects and zero inventories provide evidence in support of this assertion (Zangwill and Kantor, 1998).

\section{Quality Target}

Quality target can be set in different ways. A conventional way would be to improve the quality up to the economic conformance level, and reduce the inventory up to the level allowed by conventional ordering system such as economic order quantity. But Toyota revolutionalized the whole quality practice by choosing zero defects and zero inventories. This highlights the necessity of identifying right target, and setting it at a level that is challenging enough.

Any given process can be operated to achieve the performance target set by the management. Such target sets tone for the collective effort an organization can put towards problem solving (Zangwill and Kantor, 1986). Higher aim in the level of quality can lead a company through a steeper learning curve (Fine, 1986).

\section{Improvements Required}

Improvements required are determined by the gap between the level of current quality and the target quality (Zangwill and Kantor, 1998). The fact that improvements required are directly related to the problem definition can be highlighted by the example of Toyota mentioned above. If they had chosen the economic conformance level of quality (like everyone else) instead of zero defects, the number of defects (to be taken care of) would be quite small. 
Given the discussion above, the following proposition can be made:

Proposition IA: Problem definition directly affects improvements required.

Proposition IB: Quality target directly affects improvements required.

\section{Supervisors' Capability}

Supervisors' capability can be defined as the ability of managers and/or supervisors to identify the problem and lead the organization in implementing quality improvement programs. Supervisors need operational and conceptual skills to bring change in rules to make the quality improvement as part of the routine of organization, (Kim, 1993; Mukherjee et al., 1998).

\section{Rate Of Improvement In Process Quality}

The rate improvement depends on the quantity of improvements require and the supervisors' capability (Fine, 1986). Zangwill and Kantor (1998) use the analogy of moose and wolves. The rate of decrease of moose depends upon the number of moose (analogous to defects) and the number and effectiveness of the wolves (analogous to supervisor's capability). The process of identifying and fixing faults are powerful tools for passing quality related skills ( $\mathrm{Li}$ and Rajagopalan, 1997). Toyota treats defects as learning opportunities. Every defect is analyzed to find reasons so the same mistakes will not be repeated in future (Womack et al., 1990, page $57 \& 80$ ). Based on discussion above, two more propositions can be made.

Proposition IIA: Supervisors' skills directly affect rate of improvement in process quality. Proposition IIB: Number of problems directly affect rate of improvement in process quality.

\section{Quality Related Competitive Advantage}

Learning is cumulative process. The competitive advantage is also cumulative outcome of the improvements in process quality. Fine (1986) used the economic conformance level model to find the support for the zero defect premise. He showed that the achievement of the economic conformance level of quality increases the target optimal quality level itself. Company gets the new goal for achievements. This logic is similar to the process quality being the outcome of the cumulative quality level. The process quality in turn depends on the cumulative knowledge level (Zangwill and Kantor, 1986 and $\mathrm{Li}$ and Rajagopalan, 1998). This view is also in agreement with the resource view of the firm. Accordingly quality is one of the important assets that bestow competitive advantage to the firm over its competitor. This asset is non-tradable and can be accumulated over time choosing appropriate time flow path. It also suffers form time compression diseconomies (Diericks and Cool, 1989). Based on the discussion above, following proposition can be made:

Proposition III: The rate of improvement directly affects the quality related competitive advantage.

\section{CONCLUSION}

The theoretical model presents a consistent framework on the relationship between the managers' skills and knowledge and the process quality. The operationalization of constructs and empirical verification of proposition would be next logical step. But even at this level, some of the practical implications of the theory can be pointed out.

Quality improvement is not a one-shot exercise. It needs a sustained effort for a long time. Process quality outcome is analogous to the water in the tub; continuous learning is like opening faucet to fill water. While pace of learning can be changed, there is nothing like crash course in quality (Diericks and Cool, 1989). Because of this very nature, firms with high level of quality have a competitive advantage over their rivals (Wernerfelt, 1984; Barney, 1991). 
Quality management requires concept, skills, knowledge, and imagination. The level of quality that is achieved is the outcome of these attributes of top managers as well as middle managers (Subedi, 2002). Again, targeting of the high quality standard induces learning. And, quality is in turn affected by the cumulative learning. Once the quality ball gets rolling certain problems can be eliminated. One end leads to the new beginning that requires the identification of the new problem and establishment of new target. Here again the conceptual skills of the top mangers need to be drawn upon.

Future research should tie up the concept of quality and other aspects of improvements. For example, improvements can be required to fill the gap between the desired and actual quality level. Improvements can also be required to upgrade the product and make it more attractive even if there may not be any quality problem. Future study should explore the relationships between these two phenomena.

\section{REFERENCE}

1. Barney, J., firm Resources and Sustainable Competitive Advantage, Journal of Management, (1991) 17, pp 99-120.

2. Davenport, T. and Short, J., The New Industrial Engineering; Information Technology and business Process Redesign, Sloan Management Review (1990), Vol. 31, Issue 4, pp 11-27.

3. Dutton, J. and Thomas, A., Treating Progress Functions as a Managerial Opportunity, Academy of Management Review (1984), Volume 9, Issue 2, pp 235-247.

4. Diericks, I. and Cool, K., Asset stock accumulation and sustainability of competitive advantage, Management Science, (1989), 35 (2): 1504-1513.

5. Economist, The, Toyota The car company in front, (Jan. 27 2005), http://www.economist.com/PrinterFreindly.cfm?Story_ID=3599000.

6. Fine, C., Quality Improvement and Learning in Productive System, Management Science (1986), Vol. 32, Issue 10, pp 1301-1315.

7. Fine, C. and Raff, D., Innovation and Economic Performance in the Automobile Industry Over the Long Twentieth Century, web.mit.edu/afs/athena/org/c/ctpid/www/imvp/pub0001.htm (2001).

8. Ghemawat, P., Building Strategy on the Experience Curve, Harvard Business Review, (1985), Vol. 63, Issue 2, pp 143-149.

9. Grant, R. M., The Resource Based Theory of Competitive Advantage: Implication for Strategy Formulation, California Management Review, (1985), Vol. 63, Issue 2, pp 143-149.

10. Hatch, N. and Mowery, D., Process Innovation and Learning by Doing in Semiconductor Manufacturing, Management Science (1998), Vol. 44, Issue 11, pp 1461-1477.

11. Hendricks, K. and Singhal, V., Does Implementing and Effective TQM Program Actually Improve Operating Performance? Empirical Evidence from Firms That Have Won Quality Awards, Management Science (1997), Vol. 43, Issue 9, pp 1258-1274.

12. Helper, S., MacDuffie, J., and Sabel, C., Pragmatic Collaborations: Advancing Knowledge While Controlling Opportunism, web.mit.edu/afs/athena/org/c/ctpid/www/imvp/pub0001.htm (2000).

13. Kim, D., The Link between Individual and Organizational Learning, Sloan Management Review (1993), Vol. 35, Issue 1, pp 37-50.

14. Li, G. and Rajagopalan, S., The impact of quality learning, Journal of Operations Management (1997), Vol. 15, Issue 3, pp 181-191.

15. Li, G. and Rajagopalan, S., Process Improvement, Quality, and Learning Effects, Management Science (1998), Vol. 44, Issue 11, pp 1517-1532.

16. Mukherjee, A., Lapré, M., and Wassenhove, Knowledge Driven Quality Improvement, Management Science (1990), Vol. 44, Issue 11, pp s35-s49.

17. Power Report The, Toyota Car Topping Ford and Chevrolet? , J D Power and Associate, (2003), pp 12-17, http://www.jdpa.com/businessservices/automotive/publications/powerreport/200301/0103 Toy1.htm.

18. Senge, P., Building Learning Organizations, The Journal for Quality and Participation (1999), Vol. 22, Issue 6, pp 34-40.

19. Subedi, D. K., Developing Quality as a Source of Comparative Advantage, Mid-West DSI conference 2002. 
20. Tyre, M. and Orlikowski, W., Exploiting Opportunities for Technical Improvement in Organizations, Sloan Management Review (1993), Vol. 35, Issue 1, pp 13-26.

21. Wernerfelt, B., A Resource-based View of the Firm, Strategic Management Journal, 1984, Vol. 5, pp 171180 .

22. Womack, J., Jones, D. and Roos, D., The Machine that changed the world, Rawson Associates, New York (1990).

23. Zangwill, W. and Kantor, P., Toward a Theory of Continuous Improvement and the Learning Curve, Management Science (1998), Vol. 44, Issue 7, pp 910-920.

\section{Figure 1: The Conceptual Scheme}

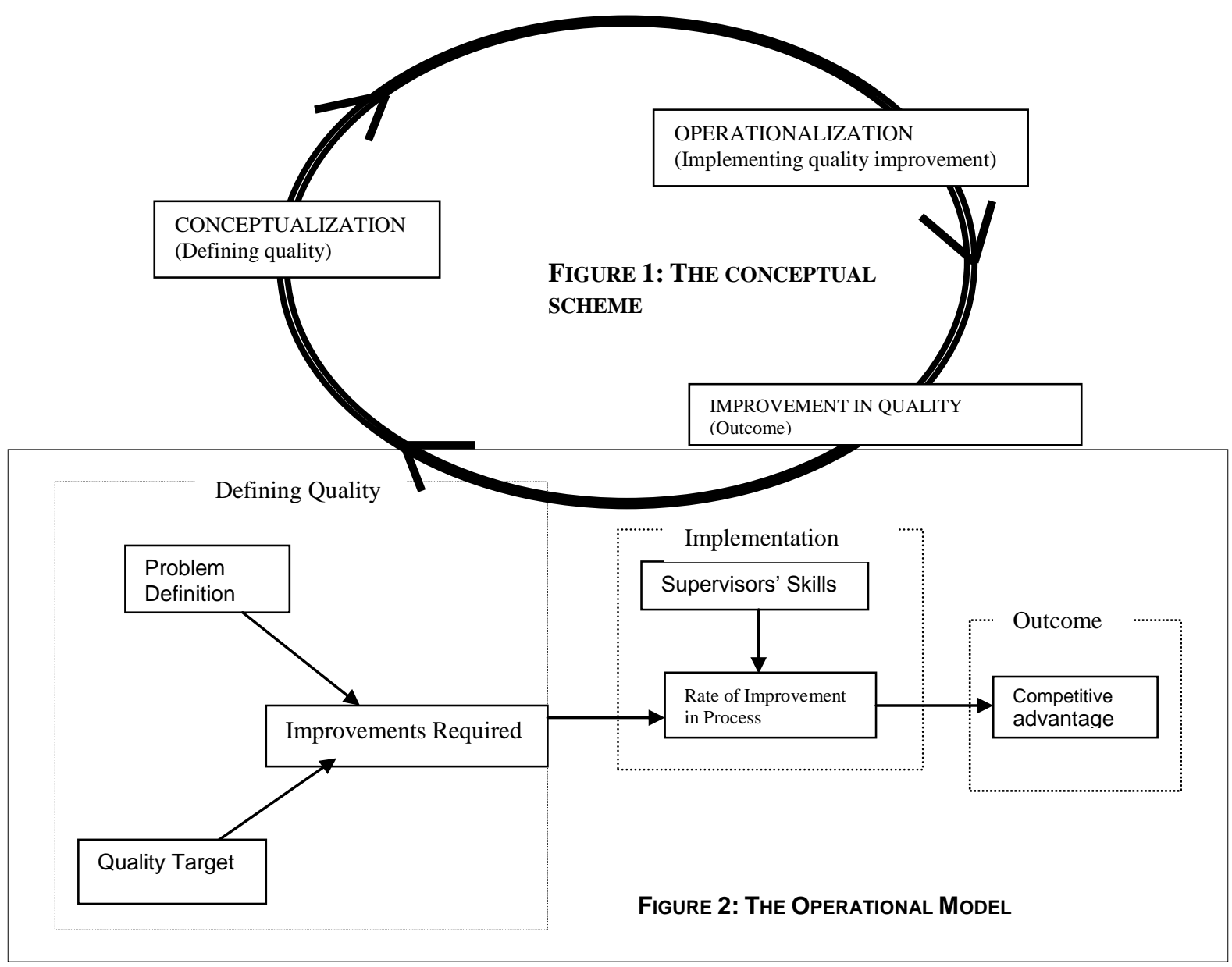

